\title{
The contribution of anxiety to the laboratory investigation of pain
}

\section{ROBERT LEPANTO, WILLIAM MORONEY AND ROBERT ZENHAUSERN}

ST. JOHN'S UNIVERSITY

\begin{abstract}
Beecher (1959) distinguished between pain and the reaction to pain. He felt that laboratory pain, since it usually involved no anxiety, was not comparable to clinical pain. This study was an attempt to introduce anxiety into a laboratory situation and study its effect on absolute pain thresholds.
\end{abstract}

\section{Introduction}

The criticism (Beecher, 1959) of the work of Hardy, Wolff, \& Goodell (1951) on pain thresholds as being abstracted from ordinary life situations is valid. When a person has control of $z$ situation, pain is more easily tolerated. This is even more evident when the D'Amour-Smith (1941) latency method is employed. Although this technique is faster and more practical it is more subject to Beec.ier's argument.

Hill (Melzak, 1961) found that a stimulus was considered significantly less painful when the $\mathrm{S}$ had full control of its onset and cessation. He showed that anxiety did indeed play a part even in a laboratory situation. Following this line of reasoning, it seemed valid to assume that any increase in anxiety would lower pain thresholds.

The present study sought to test this assumption by testing thresholds under two conditions: with S control and without $\mathrm{S}$ control. It was expected that thresholds would be lower in the "no-control" condition, reflecting the greater level of anxiety.

\section{Method}

A radiant heat dolorimeter, constructed to measure pain thresholds in latency, was modified so that the S's response would, in one case, stop the clock and the stimulus (Phase A); and in the other, stop only the clock (Phase B). In the latter condition the experimenter turned off the stimulus with a delay equal to his reaction time.

Six male and three female graduate and undergraduate students were tested on each of the two conditions. Ten spots (darkened with India ink) on each arm were stimulated three times with a $12 \mathrm{~min}$. interval between stimulations on any one spot. The order of presentation of the two phases were randomized and the entire experiment was replicated.
Separate two-way analyses of variance with replication were performed on each $\mathrm{S}$. The main effects were conditions and spots.

\section{Results and Diseussion}

In all cases the mean thresholds for Phase B were lower than those for Phase A. The analyses of variance indicated that seven of the nine were significantly different $(p<.01)$. Contrary to expectations only three of the analyses showed spots to be significant, indicating rather small inter-S variability. In no case were the spot by condition interactions significant.

The threshold data unequivocally indicated that the Phase B condition resulted in lowered thresholds. This led to the conclusion that the increase in anxiety, connected with lack of stimulus control, was an important variable in experimentation on pain. It also explained the negative results on the analgesic effects of morphine (Fangman, 1963) and codeine and Darvon (Sweeny, 1963). In both their studies anxiety was at a minimum.

It is unlikely that the data can be explained in terms of the Ss responding faster so as to make the two conditions equivalent. Subjective responses, in terms of grimaces, pilomotor responses and arm movements, indicated that the Ss did indeed find Phase B more painful even though the latency was less.

It would appear that this method is a valuable and simple procedure to make the laboratory investigation of pain more meaningful and realistic, especially in the evaluation of analgesics.

\section{References}

Beecher, H. K. The measurement of subjective responses. New York: Oxford University Press, 1959.

D'Amour, F., \& Smith, D. A method for determining the loss of pain sensation. J. pharmacol. exp. Ther., 1941, 72, 74-69.

Fangman, J. An investigation of the effects of morphine and phenobarbital on two forms of experimental pain. Unpublished doctoral dissertation. Fordham University, 1963.

Hardy, J., Wolff, H., \& Goodell, Helen. Pain sensations and reactions. Baltimore: Williams and Wilkins, 1952.

Melzak, R. The perception of pain. Scient. American, 1961, 204, 41-49.

Sweeny, D. Dolorimetry and its value as a method of evaluating agents. Unpublished doctoral dissertation. Fordham University, 1962 . 